\title{
A Special Case of Renal Duplication Diagnosed on CT Imaging
}

\author{
Zacharia Traore ${ }^{*}$, Pierlesky Elion Ossibi², Ababacar Traore1, Saeed Abdul Razak², \\ Youssef Lamrani' ${ }^{1}$, Meryem Boubbou ${ }^{1}$, Moustapha Maâroufi' ${ }^{1}$, Khalid Mazaz ${ }^{2}$, \\ Siham Tizniti' ${ }^{1}$ Imane Kamaoui ${ }^{1}$ \\ ${ }^{1}$ Radiology Department, Hassan II Teaching hospital, Fes, Morocco \\ ${ }^{2}$ Visceral Surgery Department, Hassan II Teaching Hospital, Fes, Morocco \\ Email: ztraore84@yahoo.fr
}

Received 11 January 2015; accepted 23 March 2015; published 26 March 2015

Copyright (C) 2015 by authors and Scientific Research Publishing Inc.

This work is licensed under the Creative Commons Attribution International License (CC BY). http://creativecommons.org/licenses/by/4.0/

(c) (i) Open Access

\begin{abstract}
Renal duplication or supernumerary kidney (SK) is a rare anomaly, poorly documented. It is often discovered fortuitously or after complications. Its preoperative diagnosis is difficult. We hereby report the case of a left supernumerary kidney discovered upon thoracic-abdominal pelvic CT staging in a 50-year-old woman monitored for squamous cell carcinoma of the cervix.
\end{abstract}

\section{Keywords}

\section{Renal Duplication, Supernumerary Kidney}

\section{Introduction}

Renal duplication refers to the presence of a supernumerary kidney, often separated from an ipsilatéral kidney by a unique ureter or a bifid ureter. It is a rare anomaly. Its diagnosis is often difficult [1]. Its discovery is most often fortuitous: imaging performed for diagnosing other diseases or during complications. Hence, its management therefore depends on the mode of discovery and underlying associated pathology. Very few cases have been reported in literature [2].

We report the case of a left supernumerary kidney discovered upon thoracic abdominal-pelvic CT staging in a 50-year-old woman monitored for squamous cell carcinoma of the cervix.

\section{Case}

50-year-old patient with no remarkable personal and familial history, admitted in gynecology for bleeding. His-

*Corresponding author.

How to cite this paper: Traore, Z., Ossibi, P.E., Traore, A., Razak, S.A., Lamrani, Y., Boubbou, M., Maâroufi, M., Mazaz, K., Tizniti, S. and Kamaoui, I. (2015) A Special Case of Renal Duplication Diagnosed on CT Imaging. Open Journal of Radiology, 5, 39-43. http://dx.doi.org/10.4236/ojrad.2015.51007 
tory dates back to 6 months prior to admission when patient presented minimal metrorrhagia with concomitant 6 month weight loss.

On physical examination patient was in stable condition with speculum examination revealing large cervical ulcer with irregular edges bleeding on contact. Multiple biopsies were performed. Vaginal examination revealed induration of the cervix with a right lateral mass.

Histological examination of the biopsies came back for a squamous cell carcinoma of the cervix.

Laboratory tests were suggestive of kidney failure with blood urea and creatinine 2.51 and 23 respectively. The remaining tests were unremarkable.

Renal ultrasound showed a significant uretero-hydronephrosis and thinning of the right kidney cortex with individualization of a small well-differentiated left kidney. However, with no kidney stones identified, there was a slight dilation of the left excretory cavities.

The patient was admitted to the emergencyoperation block where a double J catheter was installed and immediate post operative recovery was marked by a significant correction in blood and urea level.

Additional computed tomography revealed double left kidneys, the first normal, located in the anatomical position (lumbar), small in size measuring $7 \mathrm{~cm}$ in large diameter communicating through its ureter with the second iliac, measuring $9 \mathrm{~cm}$ in large diameter with moderate pyelocaliceal dilation (Figures 1-3) and an endo uterine fluid retention (Figure 4) upstream of an enlarged cervix coming into close contact with the rectum and lateral axis of the womb.

\section{Discussion}

Renal duplication or supernumerary kidney (SK) is a rare anomaly and before 1981, there were 63 cases reported in literature [2]. This anomaly is located in about $63.3 \%$ of cases on the left [3]. As far as embryogenesis is concerned, supernumerary kidney occurs when two ureters, separated partially or completely penetrate a blastema, hence leading to the formation of two kidneys as a result of secondary fragmentation of the metanephros [3].

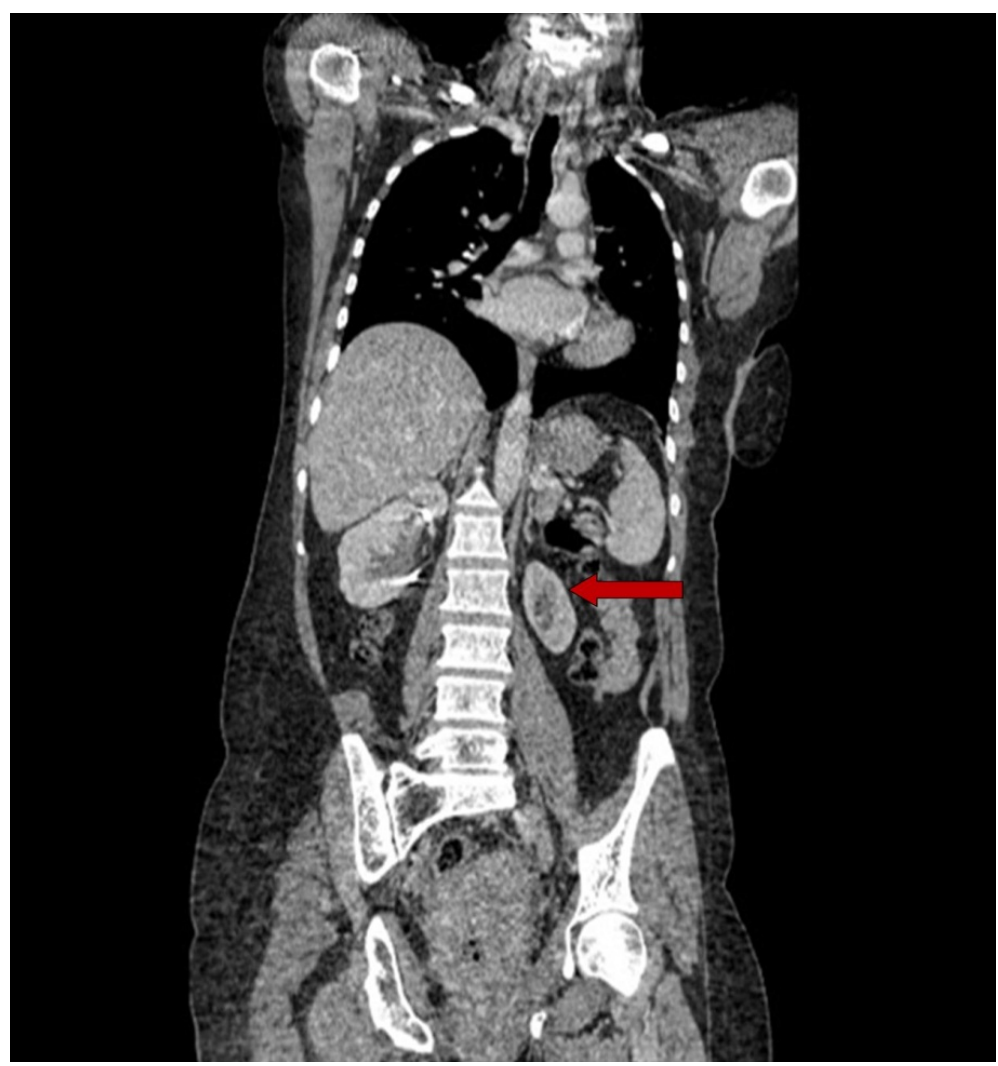

Figure 1. Small left lumbar kidney. 


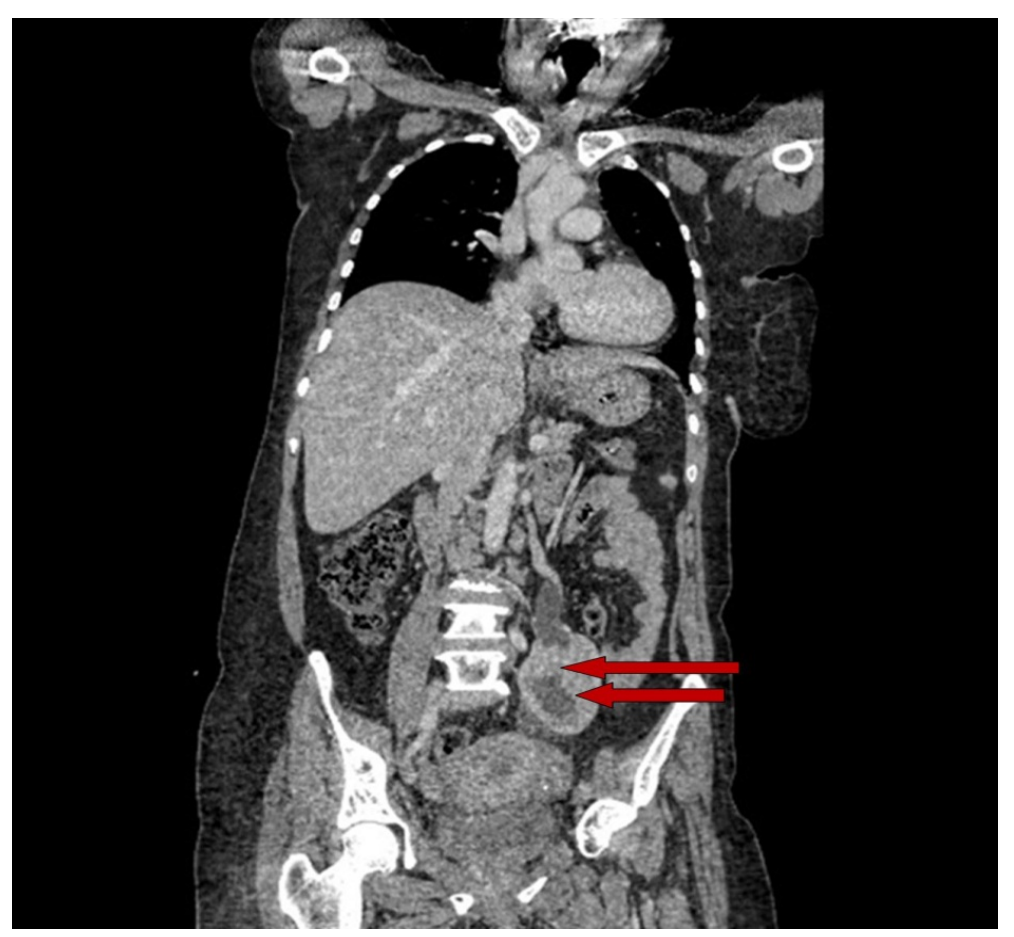

Figure 2. Left pelvic kidney.

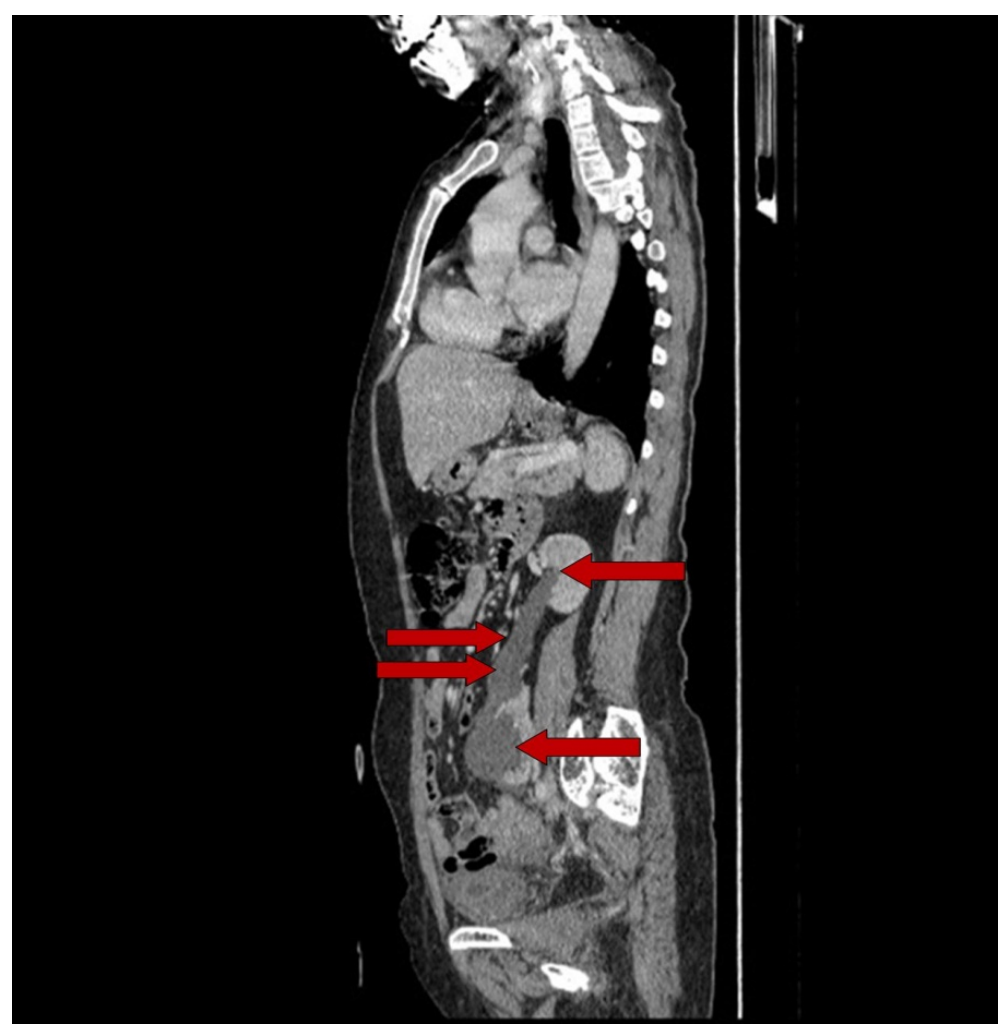

Figure 3. Left double communicating kidneys.

Supernumerary kidney (SK) can be found on the occasion of back pain, hematuria, urinary incontinence, high blood pressure or trauma [4]-[6]. It may be responsible for pelvic mass or even simulate an adrenal tumor [4] [7]. 


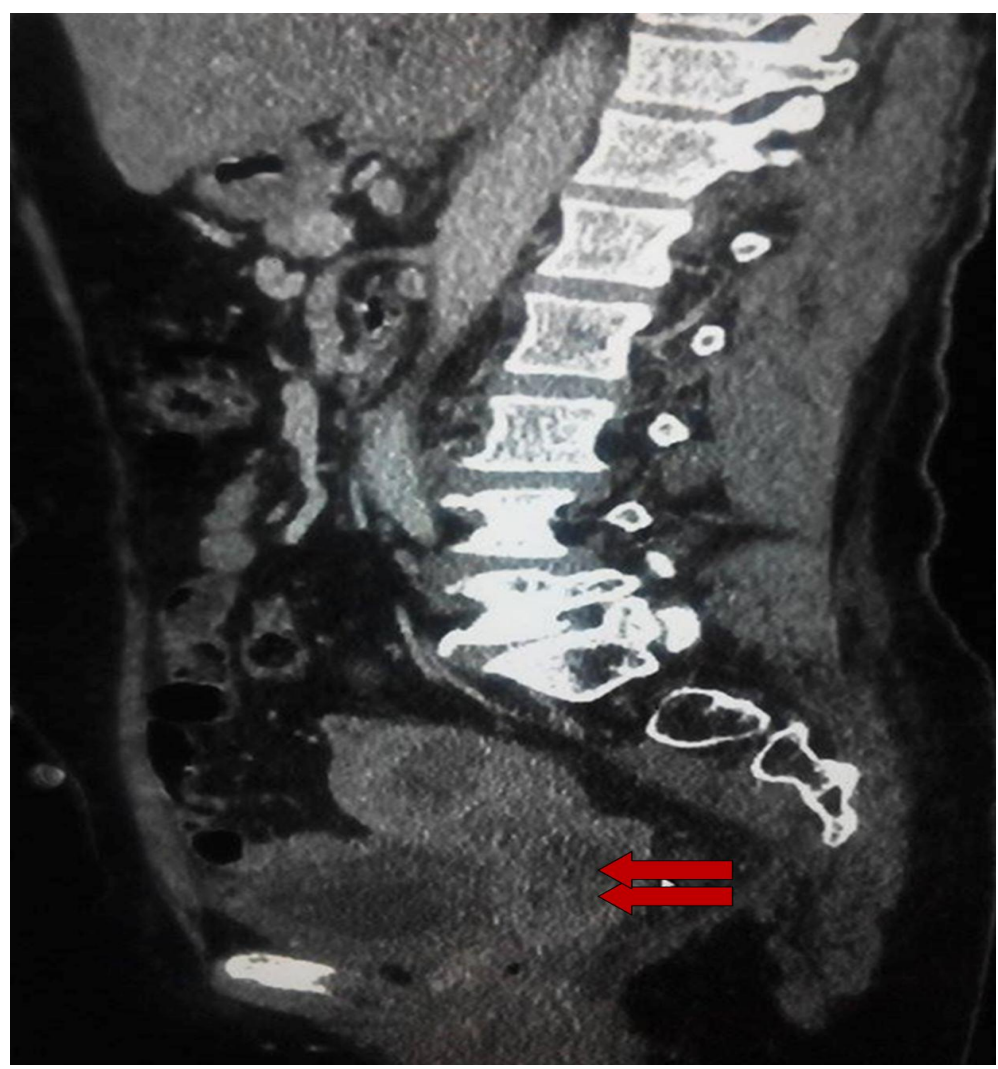

Figure 4. Enlarged cervix with fluid retention.

Its discovery is most often incidental during diagnostic imaging for other diseases or in the event of a complication.

Preoperative diagnosis of supernumerary kidney is difficult [1] [6] despite recentimaging technics including intravenous urography and even CT.

CT is the first choice imaging tool for the diagnosis of a supernumerary kidney with certitude as it shows anipsilateral kidney duplication with each kidney having a unique vascularization and excretory system. MRI may constitute a contributive diagnostic tool as it may reveal similar characteristics as evidenced in CT. Nonetheless, abdominal ultrasonography and intravenous urography may also contribute in the diagnosis of renal duplication.

In contrast to the definition of a supernumerary kidney which is the presence of a structure similar to a normal kidney in its various aspects, with a unique pedicle and a urinary tract distinct from those of the ipsilateral kidney, the particularity in our patient is that the two left kidneys were interconnected by a ureter and both drained by another ureter into the bladder: a very special feature of this renal anomaly.

Treatment [3] depends on the circumstances of discovery, the associated pathology and the state of the ipsilateral and contralateral kidneys:

-If the SK is associated with urinary incontinence due to an ectopic ureteral opening or symptomatic following stasis; infection or formation of kidney stones; nephroureterectomy is required.

-When the SK is discovered incidentally or peroperatively, nephroureterectomy could be performed if it is small, abnormal in appearance with adequate renal function of theipsilateral and contralateral kidneys.

\section{Conclusion}

Supernumerary kidney (SK) is an extremely rare abnormality usually discovered incidentally whose treatment is usually surgical and depends on the circumstances of discovery, the associated pathology and the state of the ipsilateral and contralateral kidney. 


\section{References}

[1] Youssef, A.K., Abukhadra, A.L. and Dajani, A.M. (1991) A Pitfall in Diagnosis of Supernumerary Kidney. British Journal of Urology, 67, 100. http://dx.doi.org/10.1111/j.1464-410X.1991.tb15079.x

[2] Tada, Y., Kokado, Y., Hashinaka, Y. et al. (1981) Free Supernumerary Kidney: A Case Report and Review. Journal of Urology, 126, 231-232.

[3] N'guessan, G. and Douglas, S.F. (1983) Supernumerary Kidney. Journal of Urology, 130, 649-653.

[4] Sasidharan, K., Babu, A.S., Mohan Rao, M. and Bhat, H.S. (1976) Free Supernumerary Kidney. British Journal of Urology, 48, 388. http://dx.doi.org/10.1111/j.1464-410X.1976.tb06660.x

[5] Gonzalvo, P.V., Ramada, B.F., Blasco, A.J.E., et al. (1992) Supernumerary Kidney with Ectopic Uréteral Opening to the Vagina Associated with Horseshoe Kidney. Actas UrologicasEspanolas, 16, 796-798.

[6] Koureas, A.P., Panourgias, E.C., et al. (2000) Imaging of a Supernumerary Kidney. European Radiology, 10, 17221723. http://dx.doi.org/10.1007/s003300000439

[7] Ogreid, P.I., Bo, O. and Loovas, J. (1979) Traumatic Haematuria in Supernumerary Hydronephrotic Kidney. A Case Report. Scandinavian Journal of Urology and Nephrology, 13, 127-130. http://dx.doi.org/10.3109/00365597909180013 